\title{
Indian doctors criticise health ministry's plan to curb medical "brain drain"
}

Two errors occurred in this News story by Ganapati Mudur (BMJ 2012;344:e3143, doi:10.1136/bmj.e3143) with reference to the Bulletin of the World Health Organisation study (2008;86:40) that is cited. The first inaccuracy is in the statement in the fourth paragraph that "More than half of doctors who graduated from India's top ranked medical school, the All India Institute of Medical Sciences [AIIMS], New Delhi, during the 1990 s are in the US." In fact, the study this is taken from states that: "Nearly $54 \%$ of AIIMS students who graduated during 1989-2000 now reside outside India. Of the total alumni emigrating in this group, $85.4 \%$ emigrated to the United States of America." The second error appears in the first line of the fifth paragraph: "The study had also noted that Indians make up nearly $5 \%$ of doctors in the UK and about $10 \%$ in the US." The UK and the US figures are the wrong way round in this statistic, and it should have read that Indians make up nearly $5 \%$ of doctors in the US and about $10 \%$ in the UK.

Cite this as: BMJ 2012;344:e4311

๑ BMJ Publishing Group Ltd 2012 